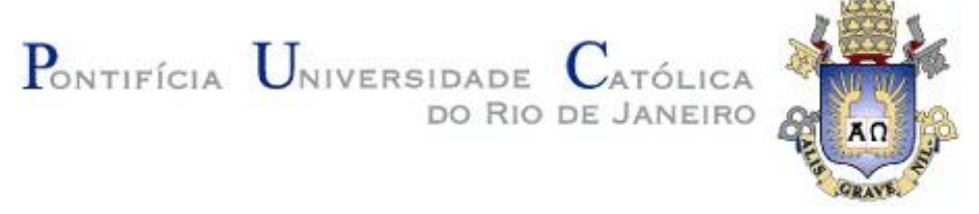

Cristian Tristão

\title{
Uma Abordagem para Modelar, Armazenar e Acessar Sequências Biológicas
}

Tese de Doutorado

Tese apresentada como requisito parcial para obtenção do título de Doutor pelo Programa de Pós-Graduação em Informática do Departamento de Informática da PUC-Rio.

Orientador: Prof. Edward Hermann Haeusler 
Cristian Tristão

\section{Uma Abordagem para Modelar, Armazenar e Acessar Sequências Biológicas}

Tese apresentada como requisito parcial para obtenção do título de Doutor pelo Programa de Pós-Graduação em Informática do Departamento de Informática da PUC-Rio. Aprovada pela Comissão Examinadora abaixo assinada.

Prof. Edward Hermann Haeusler

Orientador

PUC-Rio

Prof. Sérgio Lifschitz

PUC-Rio

Prof. Marcus V. S. Poggi de Aragão

PUC-Rio

Prof. Duncan Dubugras Alcoba Ruiz

PUCRS

Prof. Antônio Basílio de Miranda

FIOCRUZ

Prof. José Eugênio Leal

Coordenador(a) Setorial do Centro Técnico Científico - PUC-Rio

Rio de Janeiro, 09 de julho de 2012 
Todos os direitos reservados. É proibida a reprodução total ou parcial do trabalho sem autorização da universidade, do autor e do orientador.

\section{Cristian Tristão}

Possui graduação em Bacharelado em Ciência da Computação pela Pontifícia Universidade Católica do Rio Grande do Sul (2004) e mestrado em Ciência da Computação pela Pontifícia Universidade Católica do Rio Grande do Sul (2007). Tem experiência na área de Ciência da Computação, com ênfase em Banco de Dados, atuando principalmente nos seguintes temas: Biologia Computacional, Banco de Dados Biológicos e Gestão e Análise de Processos. Natural de Gravataí, Rio Grande do Sul.

Ficha Catalográfica

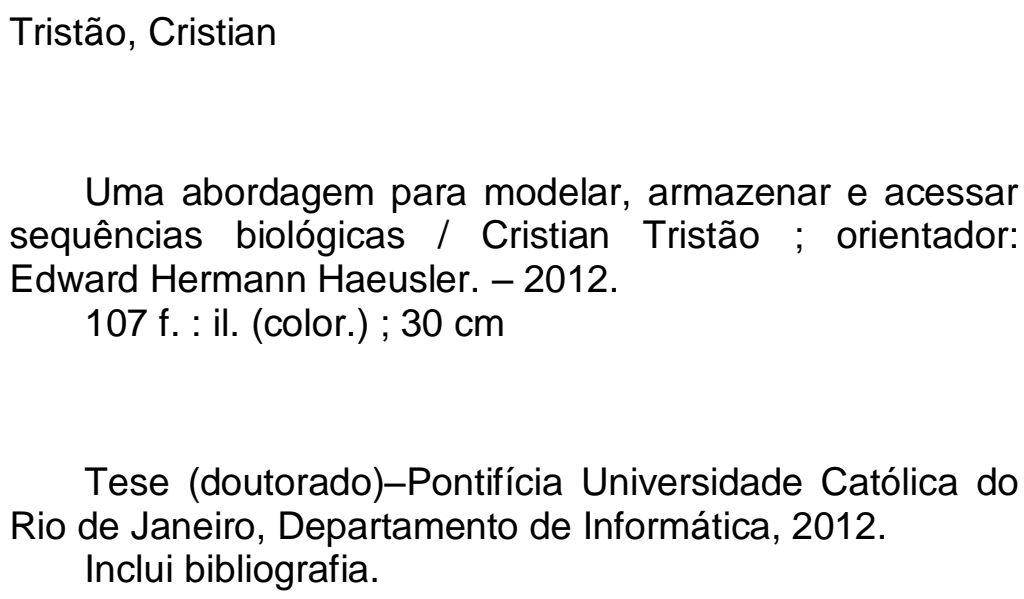

Uma abordagem para modelar, armazenar e acessar sequências biológicas / Cristian Tristão ; orientador: Edward Hermann Haeusler. - 2012.

107 f. : il. (color.) ; $30 \mathrm{~cm}$

Tese (doutorado)-Pontifícia Universidade Católica do Rio de Janeiro, Departamento de Informática, 2012.

Inclui bibliografia.

1. Informática - Teses. 2. Base de dados biológicos. 3. Modelagem conceitual de dados. 4. Estrutura de acesso e manipulação de dados biológicos. I. Haeusler, Edward Hermann. II. Pontifícia Universidade Católica do Rio de Janeiro. Departamento de Informática. III. Título. 
Aos meus pais pelo incentivo e apoio incondicional. A minha esposa, Elizabeth, pela paciência e carinho constantes. E ao meu pequeno anjo Gabriel que chegou para dar mais alegria e motivação.

"Pois te esquecerás dos teus sofrimentos e deles só terás lembrança como de águas que passaram. A tua vida será mais clara que o meio-dia; ainda que lhe haja trevas, serão como a manhã. Sentir-te-ás seguro, porque haverá esperança; olharás em derredor e dormirás tranquilo. Deitar-te-ás, e ninguém te espantará; e muitos procurarão obter o teu favor." 


\section{Agradecimentos}

À Deus por me amparar nos momentos difíceis, me dar força interior para superar as dificuldades, mostrar os caminho nas horas incertas e me suprir em todas as minhas necessidades.

À minha família, que apesar da distância sempre esteve perto e pronta para me acolher e incentivar. Esse doutorado é para você meu pai, que me ensinou que o maior legado é a educação.

Ao meu orientador, professor Sérgio Lifschitz, que acreditou no meu potencial e pela oportunidade oferecida. Em especial ao professor Hermann, que foi peça fundamental na reta final desta jornada, pela disposição e disponibilidade incondicional.

Aos professores e funcionários da Pós-Graduação, pelo excelente convívio nestes anos de trabalho. Aos amigos, professores e pesquisadores da FIOCRUZ, Antônio, Catanho e Thomas, que compartilharam grandes momentos de discussões e novas ideias.

Aos colegas, amigos e pesquisadores do Labbio, Daniel goiano, Zé Maria, Maíra, seu Paulo, Carlos Juliano, Ana Carolina, Luciana, Andreia, Márcia, Renato e Percy. Esta Tese carrega um pedaço de cada um de vocês. Peço desculpas caso tenha esquecido alguém. Também gostaria de deixar meus agradecimentos à instituição FAPERJ, pelo apoio financeiro.

À minha pastora Virgínia, que cuidou com grande carinho do meu lado espiritual.

Por fim, queria fazer um agradecimento especial a dois outros frutos desta Tese, minha esposa Elizabeth, pelo amor e apoio incondicional em todos os momentos, e ao meu pequeno anjo Gabriel, que trouxe alegria para nossas vidas e um incentivo todo especial. 


\section{Resumo}

Tristão, Cristian; Haeusler, Edward Hermann. Uma Abordagem para Modelar, Armazenar e Acessar Sequências Biológicas. Rio de Janeiro, 2012. 107 p. Tese de Doutorado - Departamento de Informática, Pontifícia Universidade Católica do Rio de Janeiro.

As pesquisas na área da biologia molecular vêm produzindo um grande volume de dados e estes precisam ser bem organizados, estruturados e persistidos. $\mathrm{Na}$ sua grande maioria os dados biológicos são armazenados em arquivos no formato texto. Para grandes volumes de dados, o caminho natural seria utilizar SGBDs para gerenciá-los. Contudo, estes sistemas não possuem estruturas adequadas para representar e manipular dados específicos ao domínio. Por exemplo, sequências biológicas normalmente são tratadas como simples cadeias de caracteres (tipo texto/varchar) ou BLOB, e desta forma perde-se todo um conjunto de informações composicionais, posicionais e de conteúdo. Esta tese argumenta que a gerência de dados (estrutura, armazenamento e acesso de dados) se transformou em um dos principais problemas para o domínio de pesquisas da bioinformática. Desta maneira propõe-se um modelo conceitual biológico para representar informações do dogma central da biologia molecular, bem como um tipo abstrato de dado (ADT - do inglês Abstract Data Types) específico para a manipulação de sequências biológicas e seus derivados.

\section{Palavras-chave}

Base de Dados Biológicos; Modelagem Conceitual de Dados; Estrutura de Acesso e Manipulação de Dados Biológicos. 


\section{Abstract}

Tristão, Cristian; Haeusler, Edward Hermann (Advisor). An Approach to Model, Store and Access Biological Sequences. Rio de Janeiro, 2012. 107 p. DSc Thesis - Departamento de Informática, Pontifícia Universidade Católica do Rio de Janeiro.

The researches in molecular biology have been producing a large amount of data and they need to be well organized, structured and persisted. Mostly biological data are stored on files in text format. For large volumes of data, the natural way would be to use DBMS to manage them. However, these systems do not have adequate structures to represent and manipulate data specific to the domain. For example, biological sequences are typically treated as simple strings (type text/varchar) or BLOB, and thus lost a whole set of compositional, positional and content information. This thesis argues that the management of data (structure, storage and data access) has become a major problem for researches in bioinformatics. Thus we propose a conceptual model for representing biological information of the central dogma of molecular biology, as well as an Abstract Data Types (ADT) specific for the manipulation of biological sequences and its derivatives.

\section{Keywords}

Biological Database; Conceptual Modeling of Data; Access Structure and Manipulation of Biological Data. 


\section{Sumário}

1 Introdução 13

1.1. Caracterização do Problema 14

1.2. Objetivos 16

1.3. Estrutura do Trabalho 16

2 Fundamentos e Trabalhos Relacionados $\quad 17$

2.1. Banco de Dados Biológico 17

2.1.1. Características dos Dados Biológicos $\quad 17$

2.1.2. Tipos de Banco de Dados Biológicos 19

2.1.3. Formas de Armazenamento e Acesso 20

2.2. Modelos de Dados Tradicionais Usados em Bioinformática 22

2.2.1. Modelo Relacional 23

2.2.2. Modelo Orientado a Objeto 26

$\begin{array}{ll}\text { 2.2.3. Modelo Semiestruturado (XML) } & 27\end{array}$

2.3. Dados Genômicos

2.3.1. Análise Comparativa de Genomas 31

2.4. Trabalhos Relacionados 33

2.4.1. Projeto Comparação de Genomas 33

2.4.2. Protein World DB 35

2.4.3. Integração de Dados 36

2.4.4. SGBDs e Extensões $\quad 39$

2.5. Considerações Finais 42

3 Proposta de Tese $\quad 44$

3.1. Modelagem, Armazenamento e Acesso de Sequências Biológicas 45

3.2. Modelo de Dados 51

3.2.1. Modelo Conceitual 51

3.3. Considerações Finais 55

4 Implementação $\quad 57$

4.1. Modelagem, Armazenamento e Acesso de Sequências Biológicas 57

4.1.1. Armazenamento de Sequências Biológicas 57 
4.1.2. Manipulação de Sequência Biológia 58

4.2. Modelo de Dados Biológicos $\quad 67$

4.2.1. Extensão do Modelo Conceitual 67

4.2.2. Modelo Lógico 68

4.2.3. Definição de Consultas

$\begin{array}{ll}\text { 4.2.4. Execução } & 90\end{array}$

4.3. Considerações Finais 95

$\begin{array}{ll}5 \text { Conclusão e Trabalhos Futuros } & 97\end{array}$

$\begin{array}{lr}\text { Referências Bibliográficas } & 100\end{array}$ 


\section{Lista de figuras}

Figura 1. Exemplo de flatfile $\quad 21$

Figura 2. Dogma central da biologia molecular $\quad 30$

Figura 3. Análise comparativa de genomas 33

Figura 4. Resultado da execução do algoritmo de Smith-Waterman 35

Figura 5. Conexões bioDBnet $\quad 37$

Figura 6. Bio2RDF: arquitetura framework do sistema 38

Figura 7. Oracle $10 \mathrm{~g}$ x BLAST 40

Figura 8. BLASTgres - representação de tipos loc e range 40

Figura 9. BLASTgres: parametrização de consultas 41

Figura 10. Diagrama conceitual $\quad 55$

Figura 11. Função isDNA $\quad 59$

Figura 12. Função complement $\quad 60$

$\begin{array}{ll}\text { Figura 13. Função reverse } & 61\end{array}$

Figura 14. Função getGCcontent. 62

Figura 15. Função transcript 63

Figura 16. Função translation $\quad 64$

Figura 17. Função searchORF 66

Figura 18. Diagrama conceitual estendido: anotações e proteínas 68

Figura 19. Mapeamento da similaridade (hits) entre proteínas e tORFs $\quad 70$

$\begin{array}{ll}\text { Figura 20. Mapeamento da taxonomia } & 71\end{array}$

Figura 21. Mapeamento do dogma central $\quad 72$

Figura 22. Mapeamento das anotações $\quad 74$

Figura 23. Protein World Database: esquema lógico 75

Figura 24. Consulta: Quantidade de Proteínas Comparadas 77

Figura 25. Consulta: Proteínas com Sequência Genômica de Origem 77

Figura 26. Consulta: Obtenção de Nodos de uma Árvore Taxonômica. 78

$\begin{array}{ll}\text { Figura 27. Função getTaxonomyldChildren. } & 78\end{array}$

Figura 28. Função getTaxonomyldChildrenSet. 79

Figura 29. Função getCountGenomeTaxonomy. 80

Figura 30. Função getCountProteinTaxonomy. 81

Figura 31. Função getCountHitsProtein. 82

Figura 32. Teoria dos conjuntos: identificação de genes únicos 84

Figura 33. Função getProteinTaxonomy. 85 
Figura 34. Função getSimilarProtein 86

$\begin{array}{ll}\text { Figura 35. Função getSingleGene } & 87\end{array}$

Figura 36. Homologia: representação de cópias parálogas e ortólogas 88

Figura 37. Função getOrthologousGene $\quad 89$

Figura 38. Função getParalogousGene. 90 


\section{Lista de tabelas}

Tabela 1. Códigos dos aminoácidos 48

Tabela 2. O sistema de tradução do código genético 49

Tabela 3. Relatório do espaço ocupado pelas tabelas do PWD 92

Tabela 4. Resultado dos testes. 95 